\title{
Phase Evolution of Oil Well Cements with Nano-Additive at Elevated Temperature/Pressure
}

\author{
by Siwei Ma, Tony Yu, Yanbin Wang, Mohend Chaouche, and Shiho Kawashima
}

\begin{abstract}
Phase characterization of Class A oil well cement slurries was performed through synchrotron X-ray diffraction technique. This allowed for real-time, in-place measurements of X-ray diffraction patterns to be obtained and, subsequently, the continuous formation and decomposition of select phases over time (up to 8 hours). Phases of interest included alite, ferrite, portlandite, ettringite, monosulfate, and jaffeite (crystalline form of calcium silicate hydrate). The effects of elevated temperatures $\left(140,185\right.$, and $300^{\circ} \mathrm{F}$ [60, 85, and $\left.149^{\circ} \mathrm{C}\right]$ ) at elevated pressure (up to approximately $15 \mathrm{ksi}[100 \mathrm{MPa}])$, as well as the effect of nanomaterial addition were investigated. Rate of conversion of ettringite to monosulfate increased with increasing temperature, and monosulfate became unstable when temperatures reached $185^{\circ} \mathrm{F}\left(85^{\circ} \mathrm{C}\right)$. The results of synchrotron X-ray diffraction provided evidence of a seeding effect introduced by nano-sized attapulgite clays at $0.5 \%$ addition by mass of cement, where acceleration in the rate of formation of portlandite and jaffeite was observed. This was supported by isothermal calorimetry results.
\end{abstract}

Keywords: high pressure; high temperature; nanomaterials; oil well cement; synchrotron; X-ray diffraction.

\section{INTRODUCTION}

For the application of oil well cementing, it is necessary to understand the phase evolution of the cement slurry during and after placement under down-hole conditions, as this has implications on the eventual sealing ability of the cement sheath. For deep-water applications, downhole temperatures and depths can reach (and exceed) $350^{\circ} \mathrm{F}\left(180^{\circ} \mathrm{C}\right)$ and $20,000 \mathrm{ft}(6000 \mathrm{~m})$, respectively. There is also hydrostatic pressure and pumping pressure being exerted onto the material, which can reach up to $22 \mathrm{ksi}(150 \mathrm{MPa})$. Therefore, it is necessary to perform characterization under elevated pressure and temperature conditions. As this presents a significant experimental challenge, especially in-place and realtime, information on phase development of oil well cement slurries at such conditions is still lacking. Synchrotron X-ray diffraction (XRD) has been employed in several studies on cement-based systems to characterize the early stages of hydration, ${ }^{1-3}$ the influence of additives on select phases, ${ }^{4,5}$ and alternate cements. ${ }^{6-8}$ Some studies have investigated oil well cement slurries with different mixture designs and additives, including silica, retarding agents, calcium chloride, and white cement, at different temperatures and pressures ${ }^{9-13}$ Fundamental hardened properties of oil well cement systems, including tensile strength, density, and shrinkage properties, under elevated temperature and pressure curing conditions, have been investigated in previous works. ${ }^{14,15}$ Further, researchers have demonstrated the coupled effect of pressure and temperature on cement hydration kinetics and phase evolution. Jupe et al. ${ }^{16}$ examined phase evolution at $0 \mathrm{ksi}$ to $8.7 \mathrm{ksi}(0$ to $60 \mathrm{MPa}), \leq 176^{\circ} \mathrm{F}\left(80^{\circ} \mathrm{C}\right)$, and Pang et al. ${ }^{17,18}$ investigated hydration kinetics under pressure $\leq 7.5 \mathrm{ksi}$ $(51.7 \mathrm{MPa})$ and temperature $\leq 140^{\circ} \mathrm{F}\left(60^{\circ} \mathrm{C}\right)$.

Numerous studies have demonstrated the potential of nanomaterials to enhance various properties of cement-based systems, including mechanical, rheological, and durability, as summarized in this review paper. ${ }^{19}$ As understanding of the effects and mechanisms of nanomaterials on the performance and microstructural properties of cement-based materials increases, researchers have begun to explore its use in specialized applications. These applications include nanosilica for impermeable coating, ${ }^{20}$ titanium dioxide nanoparticles for self-cleaning, ${ }^{21}$ carbon nanotubes for selfsensing, ${ }^{22-24}$ and nanoclays as rheological modifiers. ${ }^{25-27}$ It is possible to use nanomaterials for oil well cementing applications to tailor the flow and setting properties during the cementing process and reduce permeability to enhance sealing ability. To explore the suitability of nanomaterials in oil well cements, information on their impact on the phase evolution at elevated temperatures and pressures is needed. It is well accepted that nanomaterials have seeding effects that accelerate and promote the hydration of cement. ${ }^{28-30}$ How this seeding effect influences the phase evolution at elevated pressure and temperature conditions has not been investigated thus far and was the focus of the present study.

In the present study, a deformation-DIA (D-DIA) apparatus was used that allowed $\mathrm{XRD}$ to be performed at temperatures up to $300^{\circ} \mathrm{F}\left(149^{\circ} \mathrm{C}\right)$ and pressures reaching up to approximately $15 \mathrm{ksi}(100 \mathrm{MPa})$, for structural characterization. Fresh cement slurry was placed in the D-DIA with a synchrotron XRD setup and scanned every few minutes, thereby allowing real-time, in-place measurements up to and shortly beyond setting. From the XRD patterns, the formation and decomposition of select crystalline phases were tracked over time - namely, alite $\left(\mathrm{C}_{3} \mathrm{~S}\right)$, tetracalcium alumino ferrite $\left(\mathrm{C}_{4} \mathrm{AF}\right)$, portlandite $(\mathrm{CH})$, ettringite, monosulfate, and jaffeite. The influence of temperature and the addition of nanomaterial on the evolution of various phases was investigated. Nano-sized attapulgite clay was investi-

ACI Materials Journal, V. 113, No. 5, September-October 2016.

MS No. M-2015-077.R2, doi: 10.14359/51689104, received October 1, 2015, and reviewed under Institute publication policies. Copyright (C) 2016, American Concrete Institute. All rights reserved, including the making of copies unless permission is obtained from the copyright proprietors. Pertinent discussion including author's closure, if any, will be published ten months from this journal's date if the discussion is received within four months of the paper's print publication. 
Table 1-Chemical composition of Class A oil well cement

\begin{tabular}{l|c}
\hline $\mathrm{SiO}_{2}, \%$ & 20.1 \\
\hline $\mathrm{Al}_{2} \mathrm{O}_{3}, \%$ & 4.5 \\
\hline $\mathrm{Fe}_{2} \mathrm{O}_{3}, \%$ & 4.9 \\
\hline $\mathrm{SO}_{3}, \%$ & 2.3 \\
\hline $\mathrm{CaO}, \%$ & 63 \\
\hline $\mathrm{MgO}, \%$ & 2.5 \\
\hline $\mathrm{Na}_{2} \mathrm{O}, \%$ & - \\
\hline $\mathrm{K}_{2} \mathrm{O}, \%$ & - \\
\hline Loss of ignition, \% & 0.51 \\
\hline $\mathrm{Total}_{0} \%$ & 97.3 \\
\hline $\mathrm{C}_{3} \mathrm{~S}, \%$ & 60 \\
$\mathrm{C}_{2} \mathrm{~A}, \%$ & 4 \\
$\mathrm{C}_{4} \mathrm{AF}+2 \mathrm{C}_{3} \mathrm{~A}, \%$ & 22 \\
\hline
\end{tabular}

gated in this study, considering the potential benefits it can introduce to the cementing process as a rheological modifier.

\section{RESEARCH SIGNIFICANCE}

Information on the phase evolution of oil well cement systems at elevated pressures and temperatures is still lacking due to experimental challenges in characterization, but this information is critical to improve the cementing process in terms of efficiency and safety during these operations. Also, to explore the potential use of nanomaterials to enhance cementing performance, characterization on the effect of seeding on the microstructural properties of the setting oil well cement slurry is needed. This study implements a synchrotron-based D-DIA setup that can capture the changes in the phase evolution at early age (shortly after mixing) due to elevated pressures and temperatures that simulate downhole conditions, as well as nanomaterial addition.

\section{EXPERIMENTAL PROCEDURE}

\section{Materials}

Class A oil well cement (OWC) and tap water were used in all mixtures. Class A OWC is considered ordinary grade, where the chemical composition is comparable to that of ASTM Type I portland cement. ${ }^{31}$ The Blaine fineness is $314 \mathrm{~m}^{2} / \mathrm{kg}$ as measured through the ASTM C204 method, and its chemical composition is presented in Table 1.

Highly-purified attapulgite clays were added to select mixtures at $0.5 \%$ by mass of cement. They were commercially available clays that were chemically exfoliated from bulk attapulgite to remove all impurities. ${ }^{32}$ When dispersed, they were needle-like with an average length of $69.0 \mu \mathrm{in}$. $(1.75 \mu \mathrm{m})$ and a diameter of $0.118 \mu \mathrm{in}$. ( $3 \mathrm{~nm})$. Therefore, it can be considered a nanomaterial and will be referred to as "nanoclay" herein. In separate studies, these clays have been demonstrated to greatly enhance the level of thixotropy of cements and concretes for specialized applications. ${ }^{33-35}$ Thixotropic slurries that exhibit high flowability during pumping but then rapidly gel at rest can be beneficial for oil well cementing applications. Such properties would enable the material to effectively resist gas penetration from

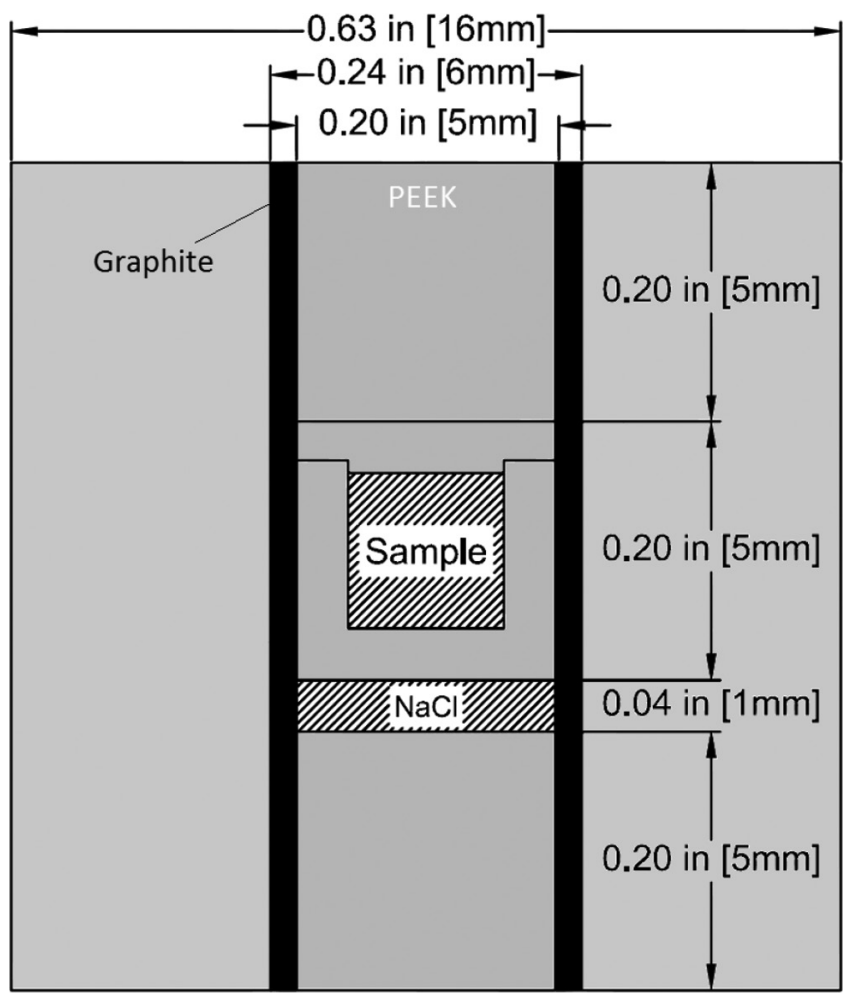

Fig. 1-Schematic of cubic sample cell assembly. Both the cube and the inner plugs are made of PEEK.

the adjacent formations during the cementing process. This period between the placement and setting of the cement sheath, known as transition time, is considered to be one of the states when the well is most vulnerable to gas migration. ${ }^{36,37}$ Although primarily used as a rheological modifier, it is necessary to investigate the effect of the clays on other performance properties at the addition levels of interest. Previous studies have investigated compressive strength ${ }^{36}$ and shrinkage. ${ }^{37}$ In the present study, the focus is on phase evolution under elevated temperature and pressure.

Cement pastes were prepared by hand-stirring for 3 minutes in a 0.85 fl. oz. $\left(25 \mathrm{~cm}^{3}\right)$ beaker with a metal spatula. When nanoclay was added, it was first blended with the mixing water in a blender for 2 minutes then added as a suspension to the cement.

\section{High-pressure, high-temperature synchrotron XRD setup}

Monochromatic synchrotron XRD tests were performed at the Advanced Photon Source (APS) in Argonne National Laboratory (ANL) on bending magnet beamline in a deformation-DIA (D-DIA) apparatus. The D-DIA allowed for elevated pressures and temperatures to be applied to the sample during testing. A brief description of the experimental setup will be given herein, but the details can be found elsewhere. ${ }^{38,39}$

The fresh slurry was loaded into the D-DIA within a cubic assembly, the schematic of which is shown in Fig. 1. After mixing, the slurry was cast in a $0.12 \times 0.12$ in. $(3 \times 3 \mathrm{~mm})$ PEEK cylindrical capsule. The capsule was vertically centered in the cubic assembly with PEEK plugs placed above and below. A layer of sodium chloride was added within to 


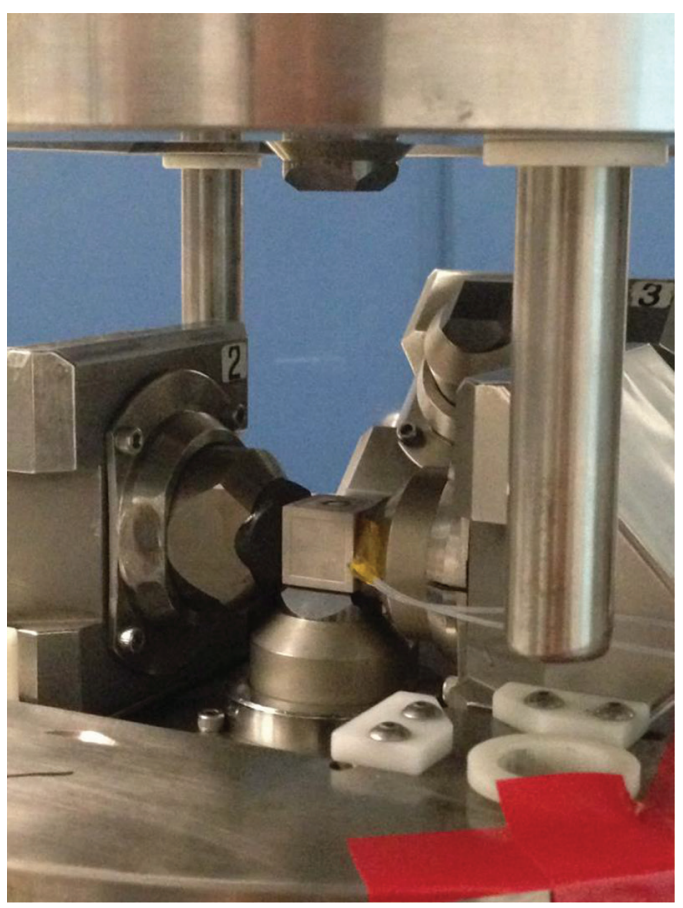

Fig. 2-Sample loading in D-DIA. The cube (with thermocouple wires protruding to the right) in the center is the assembly in which the sample was located. Some of the square-tipped anvils can also be seen.

serve as a pressure marker. A graphite heater surrounded the capsule and plugs, through which electrical resistive heating was applied. In all test runs, pressure was applied first, followed by temperature.

Pressure was introduced through a hydraulic press. Load was applied by a uniaxial hydraulic ram to the D-DIA, within which six anvils were configured to convert the uniaxial load into three orthogonal directions, thereby applying equal load to each face of the cubic assembly (Fig. 2), achieving quasi-hydrostatic pressure. A constant load of 11 tons was maintained for all samples. Calibration was performed using the sodium chloride pressure marker to obtain a measure of the pressure experienced by the slurry sample. For each run, sodium chloride's lattice constant was obtained from its XRD patterns. The pressure was then determined from the lattice parameter of sodium chloride using Brown's equation of state. ${ }^{40}$ Pressure can increase with temperature as the sample undergoes thermal expansion, or pressure can decrease with temperature as the material surrounding the sample - that is, PEEK capsule-softens and relaxes. Therefore, pressure marker measurements were taken in the middle and at the end of each run. Average marker readings indicated that the pressure of the sample was within $15 \mathrm{ksi}$ $(100 \mathrm{MPa})$ for all tests, with a standard deviation of $6.3 \mathrm{ksi}$ (43.4 MPa). Due to this uncertainty, the effect of pressure was not the focus of this paper. Development of the experimental setup to improve pressure control is ongoing.

Heat was introduced to the sample by applying an electrical power through the top and bottom anvils. Once sufficient contact was made during loading, current passed through the graphite heater in the assembly and effectively heated the sample. Calibration was performed to obtain a
Table 2-Diffraction peaks used in data analysis

\begin{tabular}{c|c|c|c}
\hline Phase & Selected peak, hkl & $d$-spacing, $\AA$ & ICDD card no. \\
\hline $\mathrm{C}_{3} \mathrm{~S}$ & 201 & 5.93 & $42-551$ \\
\hline $\mathrm{C}_{4} \mathrm{AF}$ & 001 & $\approx 7.25$ & $30-226$ \\
\hline Portlandite & 001 & 4.9 & $4-733$ \\
\hline Ettringite & 100 or 110 & 9.72 or 5.61 & $41-1451$ \\
\hline Monosulfate & 006 & 4.78 & $42-62$ \\
\hline Jaffeite & 100 & 8.69 & $77-0960$ \\
\hline Katoite & 211 & 5.05 & $77-1713$ \\
\hline
\end{tabular}

relationship between applied power and temperature of the sample, where the latter was measured through thermocouples. In all subsequent tests, temperature was calculated based on the calibration.

From initial cement and water contact, it took approximately 1 hour to load the assembly into the D-DIA and reach the targeted temperature and pressure levels. Once these levels were met, continuous XRD scans using a charge-couple area detector (approximately once every 200 seconds) were performed on the sample up to around 8 hours. Due to limitations, beamline access, and relatively long duration of each test run, one sample per mixture and temperature was tested.

\section{Isothermal calorimetry}

Rate of hydration was measured through isothermal calorimetry based on the ASTM C1679 method. A amount of $0.18 \mathrm{oz}$. (5 g) of cement paste, prepared using the same mixing protocol as the synchrotron XRD test, was cast in glass vials and loaded in the calorimeter set at target temperature. The sample was loaded into the calorimeter at the same age at which heat was introduced to reach the target temperature during the synchrotron XRD tests-approximately 1 hour after initial cement and water contact. As the heating rate was relatively fast in the synchrotron XRD test, within 5 minutes, it was assumed that the temperature history was consistent between the two test setups. Isothermal calorimetry was performed at atmospheric pressure and temperatures of 140 and $185^{\circ} \mathrm{F}\left(60\right.$ and $\left.85^{\circ} \mathrm{C}\right)$. At least three specimens were tested per mixture and temperature condition, and the average was taken to be the representative value.

\section{Data analysis}

The wavelength of X-ray used in this work was $0.3097 \AA$ $(E=40.00 \mathrm{keV})$ and the incident beam was collimated to $0.012 \times 0.012$ in. $(0.3 \times 0.3 \mathrm{~mm})$. The raw images were converted to intensity versus $d$-spacing using FIT2D. ${ }^{41}$ In selecting diffraction peaks for phase identification, the main criterion was that there was no significant overlap with other peaks. The $d$-spacing range between approximately $4.8 \AA$ to $11 \AA$, which includes all phases of interest, was chosen. The peaks that were used are presented in Table 2. The area of a single peak from each phase of interest was estimated by curve fitting with a mixture of Gaussian and Lorentzian functions. This integrated intensity (peak area) represents the amount of the phase as detected by the X-ray beam. The rapid time-resolved XRD pattern is presented in Fig. 3 to show how the relative amounts of each phase vary during 


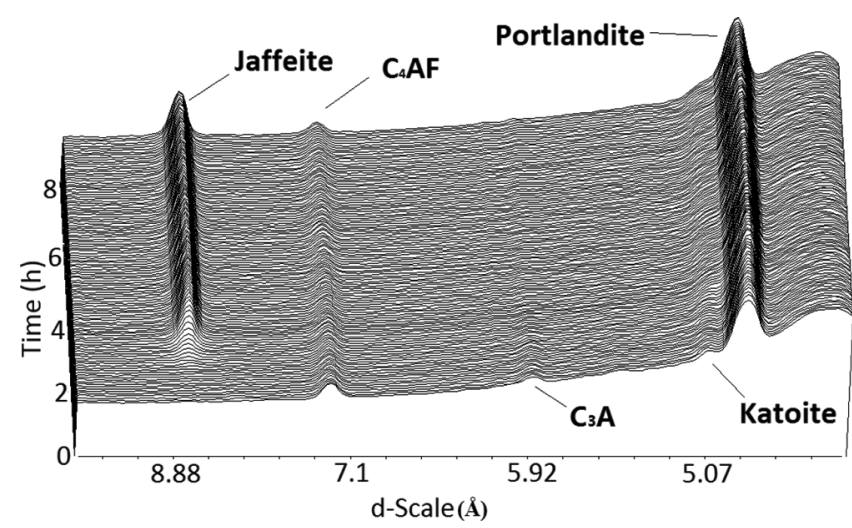

Fig. 3-X-ray diffraction patterns collected over 8 hours.

hydration. The high brilliance of the X-ray source at APS allowed for XRD patterns to be collected at a fine time resolution (approximately every 200 seconds). Also, because the slurry sample was loaded into the setup while in the fresh state, it was effectively cured in the D-DIA. Therefore, it was possible to track the crystalline phases in-place and in real-time from very early ages to beyond setting. Scans were performed on each sample for approximately 8 hours.

\section{EXPERIMENTAL RESULTS AND DISCUSSION Effect of temperature}

XRD patterns of the samples were collected at temperatures of 140,185 , and $300^{\circ} \mathrm{F}\left(60,85\right.$, and $\left.149^{\circ} \mathrm{C}\right)$. The effect of temperature on the presence of various phases in plain OWC pastes will be discussed herein. All plots, including calorimetry results, were zeroed to the time shortly after the target temperature was met-approximately 1 hour after initial cement-water contact for all mixtures. It is assumed that any changes in hydration may be considered negligible prior to this point. Generally, the XRD results capture the consumption of $\mathrm{C}_{3} \mathrm{~S}$, ferrite, and gypsum, the conversion from ettringite to monosulfate, and the formation of portlandite and jaffeite.

Figure 4 shows the evolution of phases $\mathrm{C}_{3} \mathrm{~S}$, ferrite, and gypsum at $140^{\circ} \mathrm{F}\left(60^{\circ} \mathrm{C}\right)$, each of which decrease over time due to the progression of hydration. The curves for these phases were very similar at $185^{\circ} \mathrm{F}\left(85^{\circ} \mathrm{C}\right)$ and so are not presented herein. The decrease in gypsum was detectable from the beginning and a slight plateau was observed, in agreement with other studies, ${ }^{10,42}$ around 60 minutes. This deceleration is attributed to a layer on the surface of unhydrated cement grains that initially prevents the ingress of dissolved sulfates. The plateau was then followed by a rapid decrease until gypsum was completely consumed by 125 minutes. Although no significant differences in $\mathrm{C}_{3} \mathrm{~S}$, ferrite, and gypsum were observed as an effect of increasing the temperature from 140 to $185^{\circ} \mathrm{F}\left(60\right.$ to $\left.85^{\circ} \mathrm{C}\right)$, there was an apparent change in phases ettringite and monosulfate.

The evolution of ettringite, monosulfate, and portlandite at 140 and $185^{\circ} \mathrm{F}\left(60\right.$ and $\left.85^{\circ} \mathrm{C}\right)$ are presented in Fig. 5 and Fig. 6, respectively. Synchrotron XRD tests were supplemented with isothermal calorimetry tests, where the heat-of-hydration curves are superimposed with the XRD results, and will be discussed later. As shown in Fig. 5, at

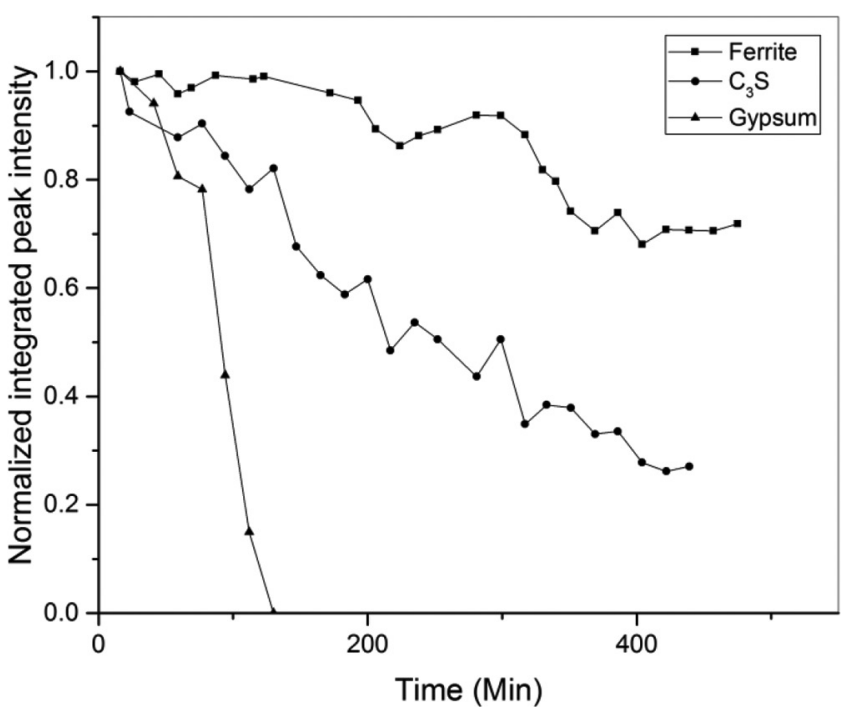

Fig. 4-Evolution of $C_{3} S$, ferrite, and gypsum in plain $\mathrm{OWC}$ at $140^{\circ} \mathrm{F}\left(60^{\circ} \mathrm{C}\right)$.

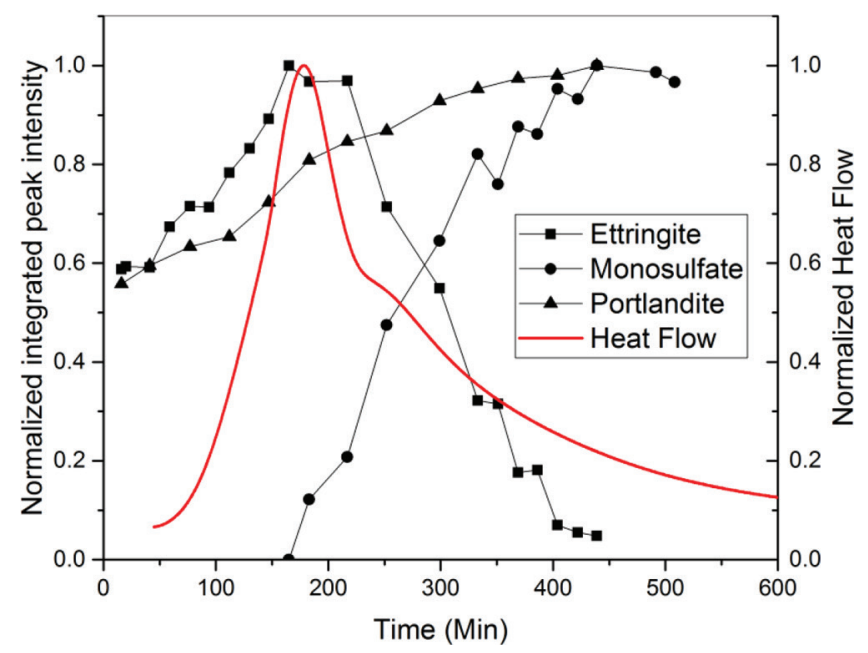

Fig. 5-Evolution of ettringite, monosulfate, and portlandite in plain $\mathrm{OWC}$ at $140^{\circ} \mathrm{F}\left(60^{\circ} \mathrm{C}\right)$, superimposed with heat-of-hydration curve.

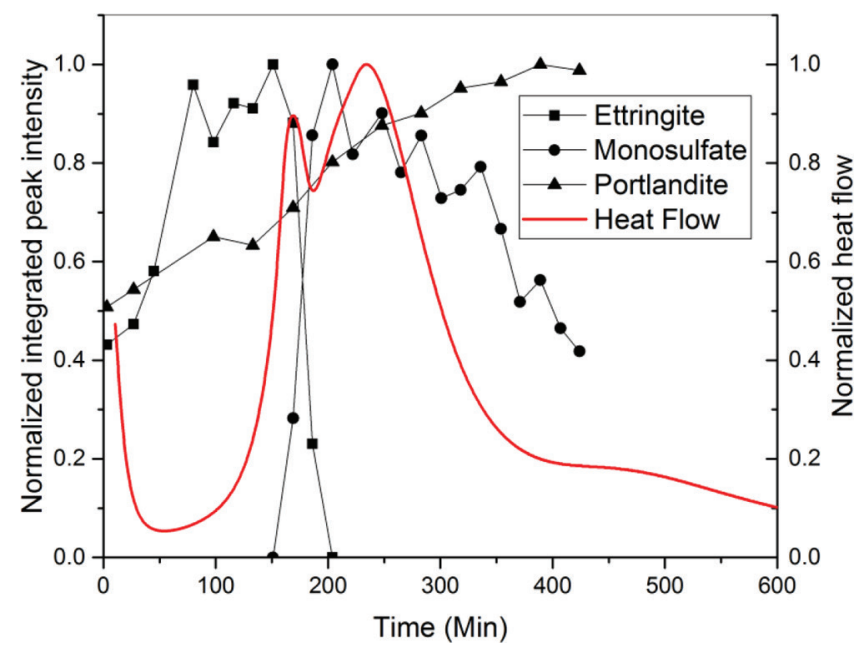

Fig. 6-Evolution of ettringite, monosulfate, and portlandite in plain $O W C$ at $185^{\circ} \mathrm{F}\left(85^{\circ} \mathrm{C}\right)$, superimposed with heat-of-hydration curve. 
$140^{\circ} \mathrm{F}\left(60^{\circ} \mathrm{C}\right)$, the decline of ettringite occurred simultaneously with the formation of monosulfate over time, up to 450 minutes, which marks the transformation of phase ettringite to phase monosulfate. This conversion did not begin immediately after gypsum was exhausted, in agreement with the observations of Jupe et al. ${ }^{12}$ This indicates that after the disappearance of solid gypsum, there was still $\mathrm{SO}_{4}{ }^{2-}$ left in the sample. Monosulfate then remained stable until the end of the experiment. In comparison, at $185^{\circ} \mathrm{F}$ $\left(85^{\circ} \mathrm{C}\right)$ (Fig. 6), ettringite-monosulfate conversion occurred much more sharply, between 150 and 200 minutes, whereas at $140^{\circ} \mathrm{F}\left(60^{\circ} \mathrm{C}\right)$, it occurred over a period of approximately 300 mintues. The kinetics of ettringite decomposition and monosulfate formation are highly dependent on temperature and pressure. ${ }^{43}$ Then, the intensity of monosulfate decreased, which is associated with the destabilization of monosulfate at $185^{\circ} \mathrm{F}\left(85^{\circ} \mathrm{C}\right)$.

The occurrence of this conversion between ettringite to monosulfate is detectable through isothermal calorimetry, as well. Heat-of-hydration curves can exhibit two peaks. The first peak indicates silicate reaction, where the main products are C-S-H and $\mathrm{CH}$. The second peak indicates aluminate reaction-namely, conversion from ettringite to monosulfate. Therefore, the rate of conversion detected by XRD can be correlated to the second peak observed by calorimetry. At $185^{\circ} \mathrm{F}\left(85^{\circ} \mathrm{C}\right)$, shown in Fig. 6 , the second peak is very prominent and occurs at approximately the same time as the ettringite-monosulfate transformation measured by XRD. On the other hand, at $140^{\circ} \mathrm{F}\left(60^{\circ} \mathrm{C}\right)$, shown in Fig. 5, there is no apparent second peak. Instead, there is a decrease in rate of deceleration, or a shoulder, that follows the first peak. This agrees with the XRD results, as the transformation from ettringite to monosulfate was found to occur much more gradually than it does at $185^{\circ} \mathrm{F}\left(85^{\circ} \mathrm{C}\right)$. It should be noted that the difference in the duration and occurrence of the conversion may be attributed to the difference in pressures and heating rates between the two test setups. Still, correlations were observable and the agreement between the $\mathrm{XRD}$ results and calorimetry results was good.

At $300^{\circ} \mathrm{F}\left(149^{\circ} \mathrm{C}\right)$, ettringite and monosulfate were not detectable. This is because their formation and decomposition occurred very rapidly during the heating period, as shown in Fig. 7. There was also the appearance of phase katoite, which has been reported to result from the decomposition of monosulfate. ${ }^{44}$ The integrated peak intensities of jaffeite, ferrite, portlandite, and $\mathrm{C}_{3} \mathrm{~S}$ at $300^{\circ} \mathrm{F}\left(149^{\circ} \mathrm{C}\right)$ are presented in Fig. 8. The accelerating effect of temperature on alite consumption was much greater at $300^{\circ} \mathrm{F}\left(149^{\circ} \mathrm{C}\right)$ than at 140 and $185^{\circ} \mathrm{F}\left(60\right.$ and $\left.85^{\circ} \mathrm{C}\right)$. Also, a marked difference from the other two temperature conditions was the presence of jaffeite. The dramatic decline of alite occurred simultaneously with the formation of jaffeite, which continued steadily over time. Jaffeite is a crystalline form of calcium silicate hydrate $(\mathrm{C}-\mathrm{S}-\mathrm{H})$, which has lower mechanical strength and higher permeability than amorphous C-S-H, and its formation is generally considered to be unfavorable. ${ }^{45}$ However, it is possible to mitigate with silica addition. ${ }^{11}$

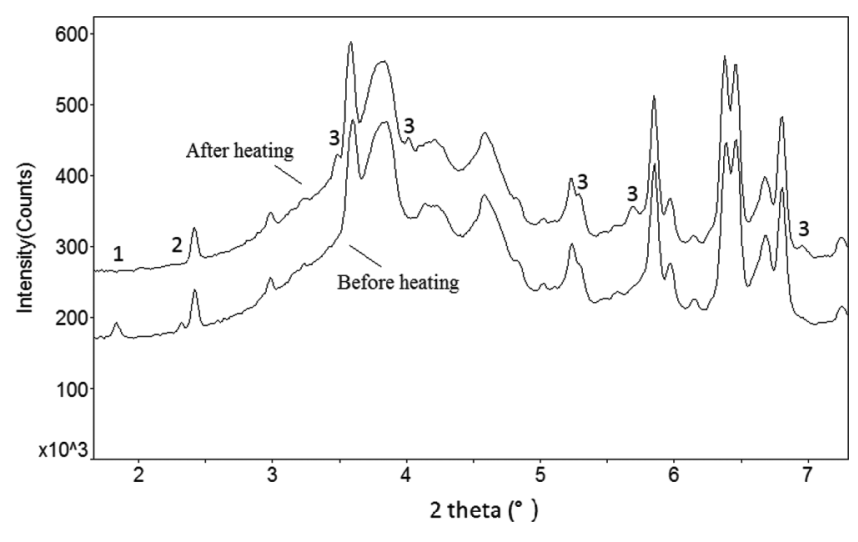

Fig. 7-X-ray diffraction patterns of plain OWC before and after heating to $300^{\circ} \mathrm{F}\left(149^{\circ} \mathrm{C}\right)$. (Note: 1. Ettringite; 2. Gypsum; and 3. Katoite.)

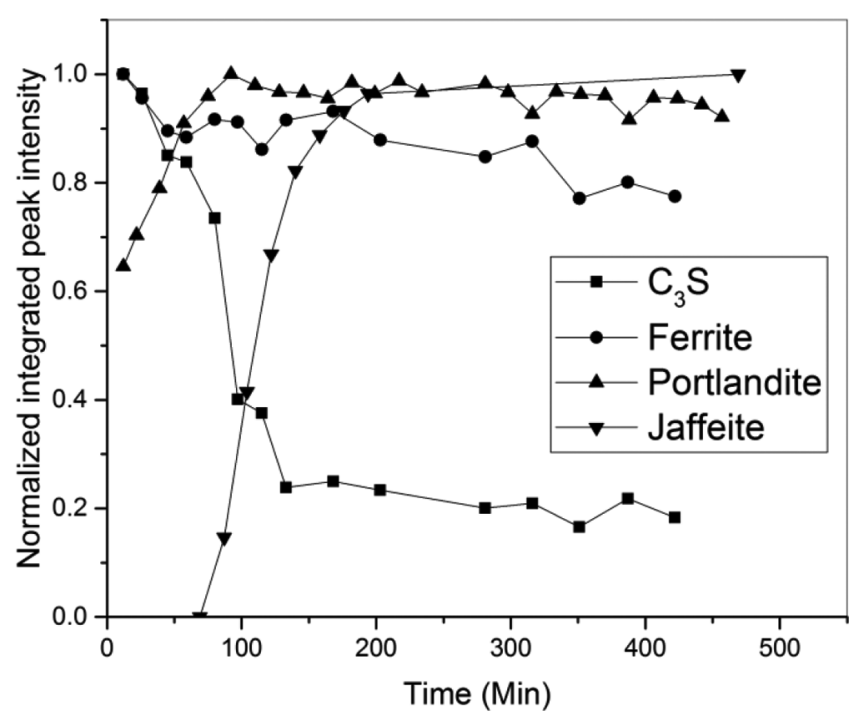

Fig. 8-Evolution of jaffeite, ferrite, portlandite, and $C_{3} S$ in plain $\mathrm{OWC}$ at $300^{\circ} \mathrm{F}\left(149^{\circ} \mathrm{C}\right)$.

\section{Effect of nano-addition}

OWC slurries with $0.5 \%$ addition of nanoclay by mass of cement were tested at temperatures of 140 and $300^{\circ} \mathrm{F}(60$ and $\left.149^{\circ} \mathrm{C}\right)$. At $140^{\circ} \mathrm{F}\left(60^{\circ} \mathrm{C}\right)$, no measurable effect by the nanoclay was observed. This may have been due to the poorly defined peaks in the XRD patterns for the phases of interest, which made it difficult to observe any subtle differences. Figure 9 shows the heat-of-hydration curves of the cement pastes with and without clay at this temperature. The age and time of loading of the paste samples were kept consistent-loaded 15 minutes after mixing - to capture the effect of the clays. Comparing the two curves, slight differences can be observed - the first peak and subsequent shoulder are higher and occur sooner for the paste with clay than the control by approximately 15 minutes. The synchrotron XRD results showed that the ettringite-monosulfate conversion occurred at the same rate. The acceleration in rate of hydration in the paste with clay this is captured through isothermal calorimetry would not have been detectable in the XRD results. However, it does provide evidence that the clays are introducing a seeding effect, although more investigation is needed to confirm. 


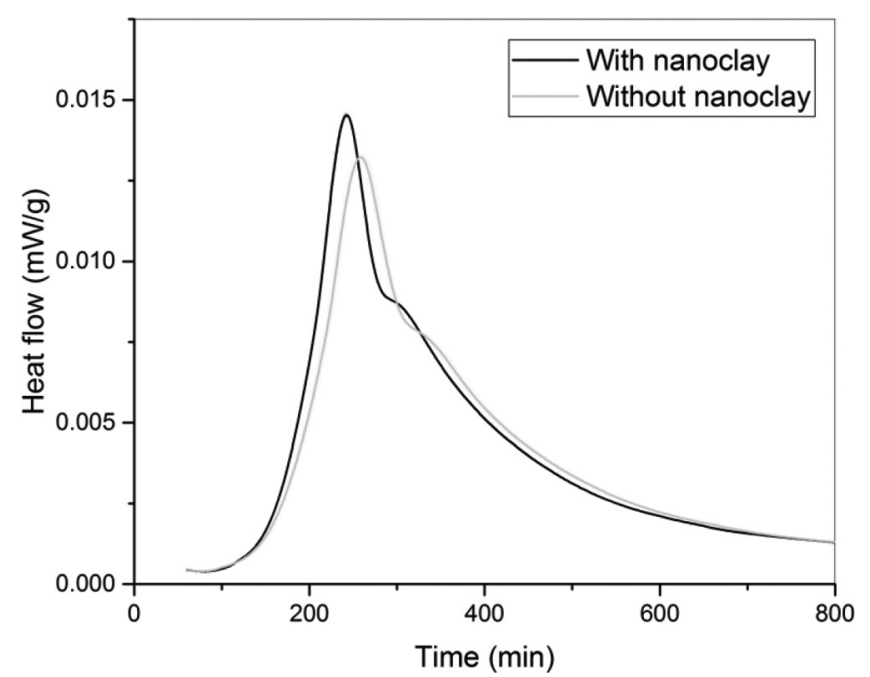

Fig. 9-Heat-of-hydration curves at $140^{\circ} \mathrm{F}\left(60^{\circ} \mathrm{C}\right)$ in $\mathrm{OWC}$ with 0 and $0.5 \%$ nanoclay addition.

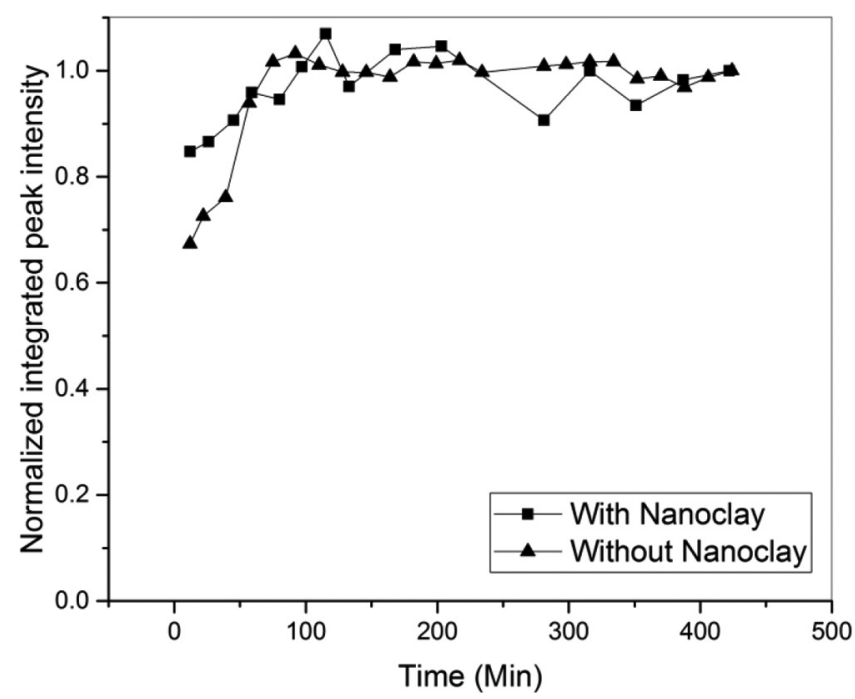

Fig. 10 -Formation of portlandite at $300^{\circ} \mathrm{F}\left(149^{\circ} \mathrm{C}\right)$ in OWC with 0 and $0.5 \%$ nanoclay addition.

Jaffeite, which formed at $300^{\circ} \mathrm{F}\left(149^{\circ} \mathrm{C}\right)$, had a very well-defined peak and the relative amounts were readily computed. The integrated peak intensities of portlandite and jaffeite at $300^{\circ} \mathrm{F}\left(149^{\circ} \mathrm{C}\right)$ are shown in Fig. 10 and 11 , respectively, comparing slurries with and without nanoclay. As shown in Fig. 10, the nanoclay led to a higher rate of portlandite formation very early on, indicating that it had an accelerating effect on hydration. Similarly, the XRD results presented in Fig. 11 show that the nanoclay accelerated the formation of jaffeite. This may potentially be attributed to a seeding effect. As aforementioned, the formation of jaffeite is not desirable and the addition of silica may mitigate its formation; these ternary systems will be the topic of future work.

\section{FURTHER RESEARCH}

A limitation of the setup used in this study was the uncertainty in the pressure exerted on the slurry sample. Continued developmental work on the setup is planned to improve pressure control. Also, slurries incorporating silica, other

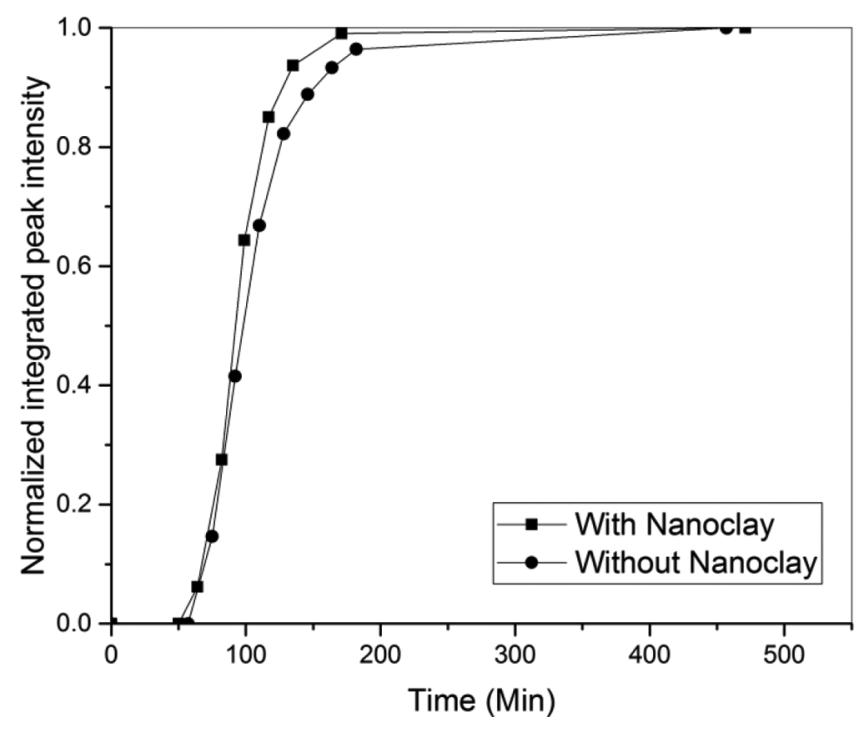

Fig. 11 -Formation of jaffeite at $300^{\circ} \mathrm{F}\left(149^{\circ} \mathrm{C}\right)$ in $\mathrm{OWC}$ with 0 and $0.5 \%$ nanoclay addition.

classes of OWC, and other types of nanomaterials would be of interest, to see if the formation of jaffeite that is caused by the nanomaterial addition can be mitigated to improve mechanical properties.

\section{CONCLUSIONS}

This study investigated the influence of temperature and addition of nano-sized attapulgite clay on the phase evolution of Class A OWC slurries. From the synchrotron XRD and isothermal calorimetry tests, the following conclusions can be drawn:

1. The synchrotron XRD test setup effectively captures the consumption of $\mathrm{C}_{3} \mathrm{~S}$, ferrite, and gypsum, the conversion from ettringite to monosulfate, and the formation of portlandite and jaffeite of fresh cement slurries. Increasing temperature from 140 to $300^{\circ} \mathrm{F}\left(60\right.$ to $149^{\circ} \mathrm{C}$ ) leads to acceleration in portlandite formation and ettringite-monosulfate conversion. At $300^{\circ} \mathrm{F}\left(149^{\circ} \mathrm{C}\right)$, the formation of jaffeite occurs.

2. The ettringite-monosulfate conversion at 140 and $300^{\circ} \mathrm{F}$ $\left(60\right.$ and $149^{\circ} \mathrm{C}$ ) in the XRD results agreed well with the appearance of the second peak in heat-of-hydration curves measured by isothermal calorimetry. Discrepancies between the results can be attributed to the difference in pressure and heating rate between the two test setups.

3. The nanoclay led to measurable acceleration in jaffeite and portlandite formation at $300^{\circ} \mathrm{F}\left(149^{\circ} \mathrm{C}\right)$. This can potentially be due to a seeding effect, which is commonly observed when incorporating nanomaterials into cementitious systems. As jaffeite is undesirable, leading to an increase in permeability, this is an important mixture design consideration when incorporating attapulgite clays or other nanomaterials for oil well cementing applications. Incorporating silica to mitigate jaffeite formation and promote amorphous C-S-H growth in systems modified with nanomaterials warrants investigation.

\section{AUTHOR BIOS}

ACI member Siwei Ma is a PhD Student in the Civil Engineering and Engineering Mechanics Department, Columbia University, New York. He 
received his BS from Shenyang Jianzhu University, Shenyang, China, and his MS from Columbia University. His research interests include phase evolution and rheological behavior of cement slurries at high temperature and high pressure conditions.

Tony Yu is a Research Beamline Scientist of the Center for Advanced Radiation Sources, Physical Science Division at the University of Chicago, Chicago, IL. He received his BS from Chinese Culture University, Taipei, Taiwan; MS from National Taiwan University, Taipei, Taiwan; and PhD from Stony Brook University, New York. His research interests include physical properties and structure study of high-pressure and high-temperature amorphous materials using synchrotron X-ray.

Yanbin Wang is a Senior Scientist at the University of Chicago. He received his BS from Peking University, Beijing, China, and PhD from Stony Brook University. His research interests include materials structure and properties under high pressure and temperature, as well as synchrotron instrumentation for high-pressure research.

Mohend Chaouche is a Research Director at the French National Center for Scientific Research (CNRS), Paris, France. He received his MS and PhD from Pierre and Marie Curie University, Paris France. His research interests include rheology of complex fuids, including cement-based materials.

ACI Member Shiho Kawashima is an Assistant Professor of civil engineering and engineering mechanics at Columbia University. She received her BS from Columbia University and MS and PhD from Northwestern University, Evanston, IL. She is a member of ACI Committees 236, Material Science of Concrete; 237, Self-Consolidating Concrete; 238, Workability of Fresh Concrete; and 241, Nanotechnology of Concrete. Her research interests include cement and concrete rheology, and the use of nanomaterials in cement-based systems.

\section{ACKNOWLEDGMENTS}

The authors would like to acknowledge the National Science Foundation (NSF EEC-1342377) for financial support, and the Advanced Photon Source at Argonne National Laboratory for providing beamtime. Portions of this work were performed at GeoSoilEnviroCARS (Sector 13), Advanced Photon Source (APS), Argonne National Laboratory. GeoSoilEnviroCARS is supported by the National Science Foundation - Earth Sciences (EAR-1128799) and Department of Energy - GeoSciences (DE-FG0294ER14466). This research used resources of the Advanced Photon Source, a U.S. Department of Energy (DOE) Office of Science User Facility operated for the DOE Office of Science by Argonne National Laboratory under Contract No. DE-AC02-06CH11357.

\section{REFERENCES}

1. Clark, S. M., and Barnes, P. A., "Comparison of Laboratory, Synchrotron and Neutron Diffraction for the Real Time Study of Cement Hydration," Cement and Concrete Research, V. 25, No. 3, 1995, pp. 639-646. doi: 10.1016/0008-8846(95)00052-E

2. Evju, C., and Hansen, S., "Expansive Properties of Ettringite in a Mixture of Calcium Aluminate Cement, Portland Cement and $\beta$-Calcium Sulfate Hemihydrate," Cement and Concrete Research, V. 31, No. 2, 2001, pp. 257-261. doi: 10.1016/S0008-8846(00)00495-6

3. Rashid, S.; Barnes, P.; Bensted, J.; and Turrillas, X., "Conversion of Calcium Aluminate Cement Hydrates Re-examined with Synchrotron Energy-Dispersive Diffraction," Journal of Materials Science Letters, V. 13, No. 17, 1994, pp. 1232-1234. doi: 10.1007/BF00270944

4. Merlini, M.; Artioli, G.; Meneghini, C.; Cerulli, T.; Bravo, A.; and Cella, F., "The Early Hydration and the Set of Portland Cements: In Situ X-Ray Powder Diffraction Studies," Powder Diffraction, V. 22, No. 3, 2007, pp. 201-208. doi: 10.1154/1.2754713

5. Weyer, H. J.; Müller, I.; Schmitt, B.; Bosbach, D.; and Putnis, A., "Time-Resolved Monitoring of Cement Hydration: Influence of Cellulose Ethers on Hydration Kinetics," Nuclear Instruments \& Methods in Physics Research. Section B, Beam Interactions with Materials and Atoms, V. 238, No. 1-4, 2005, pp. 102-106. doi: 10.1016/j.nimb.2005.06.026

6. Oh, J. E.; Monteiro, P. J. M.; Jun, S. S.; Choi, S.; and Clark, S. M., "The Evolution of Strength and Crystalline Phases for Alkali-Activated Ground Blast Furnace Slag and Fly Ash-Based Geopolymers," Cement and Concrete Research, V. 40, No. 2, 2010, pp. 189-196. doi: 10.1016/j. cemconres.2009.10.010

7. Snellings, R.; Mertens, G.; Cizer, Ö.; and Elsen, J., "Early Age Hydration and Pozzolanic Reaction in Natural Zeolite Blended Cements: Reaction Kinetics and Products by In Situ Synchrotron X-Ray Powder Diffrac- tion," Cement and Concrete Research, V. 40, No. 12, 2010, pp. 1704-1713. doi: 10.1016/j.cemconres.2010.08.012

8. Williams, P. J.; Biernacki, J. J.; Rawn, C. J.; Walker, L.; and Bai, J., "Microanalytical and Computational Analysis of Class F Fly Ash," ACI Materials Journal, V. 102, No. 5, Sept.-Oct. 2005, pp. 330-337.

9. Jupe, A. C.; Wilkinson, A. P.; and Funkhouser, G. P., "Simultaneous Study of Mechanical Property Development and Early Hydration Chemistry in Portland Cement Slurries Using X-Ray Diffraction and Ultrasound Reflection," Cement and Concrete Research, V. 42, No. 8, 2012, pp. 11661173. doi: 10.1016/j.cemconres.2012.05.013

10. Jupe, A. C.; Wilkinson, A. P.; Luke, K.; and Funkhouser, G. P., “Class $\mathrm{H}$ Oil Well Cement Hydration at Elevated Temperatures in the Presence of Retarding Agents:An In Situ High-Energy X-Ray Diffraction Study," Industrial \& Engineering Chemistry Research, V. 44, No. 15, 2005, pp. 5579-5584. doi: $10.1021 / \mathrm{ie} 049085 \mathrm{t}$

11. Jupe, A. C.; Wilkinson, A. P.; Luke, K.; and Funkhouser, G. P., "Class $\mathrm{H}$ Cement Hydration at $180^{\circ} \mathrm{C}$ and High Pressure in the Presence of Added Silica," Cement and Concrete Research, V. 38, No. 5, 2008, pp. 660-666. doi: 10.1016/j.cemconres.2007.12.004

12. Jupe, A. C.; Wilkinson, A. P.; Luke, K.; and Funkhouser, G. P., "Slurry Consistency and In Situ Synchrotron X-Ray Diffraction During the Early Hydration of Portland Cements With Calcium Chloride," Journal of the American Ceramic Society, V. 90, No. 8, 2007, pp. 2595-2602. doi: 10.1111/j.1551-2916.2007.01806.x

13. Colston, S. L.; Barnes, P.; Jupe, A. C.; Jacques, S. D. M.; Hall, C.; Livesey, P.; Dransfield, J.; Meller, N.; and Maitland, G. C., "An In Situ Synchrotron Energy-Dispersive Diffraction Study of the Hydration of Oilwell Cement Systems under High Temperature/Autoclave Conditions up to $130^{\circ} \mathrm{C}$," Cement and Concrete Research, V. 35, No. 12, 2005, pp. 2223-2232. doi: 10.1016/j. cemconres.2004.09.005

14. Pang, X.; Meyer, C.; Funkhouser, G. P.; and Darbe, R., "An Innovative Test Apparatus for Oil Well Cement: In-Situ Measurement of Chemical Shrinkage and Tensile Strength," Construction \& Building Materials, V. 74, 2015, pp. 93-101. doi: 10.1016/j.conbuildmat.2014.10.025

15. Pang, X., "Effects of Curing Temperature and Pressure on the Chemical, Physical, and Mechanical Properties of Portland Cement," PhD dissertation thesis, Columbia University, New York, 2011, 239 pp.

16. Jupe, A. C.; Wilkinson, A. P.; and Funkhouser, G. P., "Oil-Well Cement and $\mathrm{C}_{3} \mathrm{~S}$ Hydration Under High Pressure as Seen by In Situ X-Ray Diffraction, Temperatures $\leq 80^{\circ} \mathrm{C}$ with No Additives," Journal of the American Ceramic Society, V. 94, No. 5, 2011, pp. 1591-1597. doi: 10.1111/j.1551-2916.2010.04284.x

17. Pang, X.; Cuello Jimenez, W.; and Iverson, B. J., "Hydration Kinetics Modeling of the Effect of Curing Temperature and Pressure on the Heat Evolution of Oil Well Cement," Cement and Concrete Research, V. 54, 2013, pp. 69-76. doi: 10.1016/j.cemconres.2013.08.014

18. Pang, X.; Meyer, C.; Darbe, R.; and Funkhouser, G. P., "Modeling the Effect of Curing Temperature and Pressure on Cement Hydration Kinetics," ACI Materials Journal, V. 110, No. 2, Mar.-Apr. 2013, pp. 137-148.

19. Sanchez, F., and Sobolev, K., "Nanotechnology in Concrete-A Review," Construction \& Building Materials, V. 24, No. 11, 2010, pp. 20602071. doi: 10.1016/j.conbuildmat.2010.03.014

20. Hou, P.; Cheng, X.; Qian, J.; Zhang, R.; Cao, W.; and Shah, S. P., "Characteristics of Surface-Treatment of Nano- $\mathrm{SiO}_{2}$ on the Transport Properties of Hardened Cement Pastes with Different Water-to-Cement Ratios," Cement and Concrete Composites, V. 55, 2015, pp. 26-33. doi: 10.1016/j. cemconcomp.2014.07.022

21. Chen, J.; Kou, S.; and Poon, C., "Photocatalytic Cement-Based Materials: Comparison of Nitrogen Oxides and Toluene Removal Potentials and Evaluation of Self-Cleaning Performance," Building and Environment, V. 46, No. 9, 2011, pp. 1827-1833. doi: 10.1016/j.buildenv.2011.03.004

22. Azhari, F., and Banthia, N., "Cement-Based Sensors with Carbon Fibers and Carbon Nanotubes for Piezoresistive Sensing," Cement and Concrete Composites, V. 34, No. 7, 2012, pp. 866-873. doi: 10.1016/j. cemconcomp.2012.04.007

23. Yu, X., and Kwon, E., "A Carbon Nanotube/Cement Composite with Piezoresistive Properties," Smart Materials and Structures, V. 18, No. 5, 2009. doi: 10.1088/0964-1726/18/5/055010

24. Han, B.; Yu, X.; and Kwon, E., "A Self-Sensing Carbon Nanotube/ Cement Composite for Traffic Monitoring," Nanotechnology, V. 20, No. 44, 2009. doi: $10.1088 / 0957-4484 / 20 / 44 / 445501$

25. Kawashima, S.; Chaouche, M.; Corr, D. J.; and Shah, S. P., "Rate of Thixotropic Rebuilding of Cement Pastes Modified with Highly Purified Attapulgite Clays," Cement and Concrete Research, V. 53, 2013, pp. 112-118. doi: 10.1016/j.cemconres.2013.05.019

26. Kawashima, S.; Chaouche, M.; Corr, D. J.; and Shah, S. P., "Influence of Purified Attapulgite Clays on the Adhesive Properties of Cement Pastes as Measured by the Tack Test," Cement and Concrete Composites, V. 48, 2014, pp. 35-41. doi: 10.1016/j.cemconcomp.2014.01.005 
27. Tregger, N. A.; Pakula, M. E.; and Shah, S. P., "Influence of Clays on the Rheology of Cement Pastes," Cement and Concrete Research, V. 40, No. 3, 2010, pp. 384-391. doi: 10.1016/j.cemconres.2009.11.001

28. Land, G., and Stephan, D., "The Influence of Nano-Silica on the Hydration of Ordinary Portland Cement," Journal of Materials Science, V. 47, No. 2, 2012, pp. 1011-1017. doi: 10.1007/s10853-011-5881-1

29. Sato, T., and Diallo, F., "Seeding Effect of $\mathrm{Nano}_{-} \mathrm{CaCO}_{3}$ on the Hydration of Tricalcium Silicate," Transportation Research Record: Journal of the Transportation Research Board, V. 2141, 2010, pp. 61-67. doi: 10.3141/2141-11

30. Thomas, J. J.; Jennings, H. M.; and Chen, J. J., "Influence of Nucleation Seeding on the Hydration Mechanisms of Tricalcium Silicate and Cement," The Journal of Physical Chemistry C, V. 113, No. 11, 2009, pp. 4327-4334. doi: 10.1021/jp809811w

31. Nelson, E. B., Well Cementing, Elsevier Science, 1990, 1515 pp.

32. Active Minerals Company LLC, "What is Acti-Gel 208 and How Is It Made?" 2007.

33. Kim, J. H.; Beacraft, M.; and Shah, S. P., "Effect of Mineral Admixtures on Formwork Pressure of Self-Consolidating Concrete," Cement and Concrete Composites, V. 32, No. 9, 2010, pp. 665-671. doi: 10.1016/j. cemconcomp.2010.07.018

34. Pekmezci, B. Y.; Voigt, T.; Wang, K.; and Shah, S. P., "Low Compaction Energy Concrete for Improved Slipform Casting of Concrete Pavements," ACI Materials Journal, V. 104, No. 3, May-June 2007, pp. 251-258.

35. Quanji, Z.; Lomboy, G. R.; and Wang, K., "Influence of Nano-Sized Highly Purified Magnesium Alumino Silicate Clay on Thixotropic Behavior of Fresh Cement Pastes," Construction \& Building Materials, V. 69, 2014, pp. 295-300. doi: 10.1016/j.conbuildmat.2014.07.050

36. Economides, M.; Watters, L. T.; and Dunn-Norman, S., Petroleum Well Construction, Wiley, 1998, 640 pp.
37. Bartlit, J.; Sankar, S.; and Grimsley, S., "Macondo-The Gulf Oil Disaster," Chief Counsel's Report, National Commission on the BP Deepwater Horizon Oil Spill and Offshore Drilling, 2011.

38. Wang, Y.; Durham, W. B.; Getting, I. C.; and Weidner, D. J., "The Deformation-DIA: A New Apparatus for High Temperature Triaxial Deformation to Pressures up to $15 \mathrm{GPa}$," The Review of Scientific Instruments, V. 74, No. 6, 2003, pp. 3002-3011. doi: 10.1063/1.1570948

39. Wang, Y.; Uchida, T.; Westferro, F.; Rivers, M. L.; Nishiyama, N.; Gebhardt, J.; Lesher, C. E.; and Sutton, S. R., "High-Pressure X-Ray Tomography Microscope: Synchrotron Computed Microtomography at High Pressure and Temperature," The Review of Scientific Instruments, V. 76, No. 7, 2005, p. 073709. doi: 10.1063/1.1979477

40. Brown, J. M., “The NaCl Pressure Standard," Journal of Applied Physics, V. 86, No. 10, 1999, pp. 5801-5808. doi: 10.1063/1.371596

41. Hammersley, A. P.; Svensson, S. O.; Hanfland, M.; Fitch, A. N.; and Hausermann, D., "Two-Dimensional Detector Software: From Real Detector to Idealised Image or Two-Theta Scan," High Pressure Research, V. 14, No. 4-6, 1996, pp. 235-248. doi: 10.1080/08957959608201408

42. Luke, K., and Glasser, F. P., "Chemical Changes Occurring During the Early Hydration of PFA-OPC Mixtures," MRS Proceedings, V. 65, 1985, doi: 10.1557/PROC-65-173.

43. Taylor, H., Cement Chemistry, Thomas Telford Publishing, 1997.

44. Meller, N.; Kyritsis, K.; and Hall, C., "The Hydrothermal Decomposition of Calcium Monosulfoaluminate 14-Hydrate to Katoite Hydrogarnet and $\beta$-Anhydrite: An In-Situ Synchrotron X-Ray Diffraction Study," Journal of Solid State Chemistry, V. 182, No. 10, 2009, pp. 2743-2747. doi: 10.1016/j.jssc.2009.07.029

45. Barnes, P., and Bensted, J., Structure and Performance of Cements, CRC Press, 2002 